\title{
El mapa de la Relación Geográfica de Zapotitlán (1579): una isla de racionalidad en un océano de empirismo
}

\author{
Manuel Morato Moreno \\ Departamento de Ingeniería Gráfica \\ Universidad de Sevilla (España)
}

\begin{abstract}
Resumen
En el proceso de colonización de América fue necesaria la representación de su territorio, empresa en la que surgió un nuevo estilo cartográfico híbrido, que mezclaba convenciones españolas e indígenas, así como otras nuevas que nacieron como consecuencia de las influencias mutuas entre culturas. La mayoría de los mapas que trazaron tanto indígenas como colonizadores durante el siglo XVI, no se ajustaron a los cánones cartográficos utilizados en la Europa renacentista. En este extenso corpus encontramos un caso excepcional, pues reúne todas las características de la representación científica, tal como los cosmógrafos de la Corona española esperaban que se cartografiasen los nuevos territorios ultramarinos: el mapa de Zapotitlán. Aunque el documento ya ha sido estudiado por diversos autores, este trabajo incide especialmente en los procedimientos cartográficos, con nuevas aportaciones como el análisis de los sistemas de representación utilizados, la extensión de la región representada o la determinación de la escala.

Palabras clave: cartografía cientifica, mapa topográfico, Guatemala, siglo XVI.
\end{abstract}

\begin{abstract}
In the Spanish colonization of America, representation of its territory became a necessity, a process in which a new hybrid style of cartography arose, that mixed Spanish and indigenous conventions as well as new ones, a result of mutual influences between cultures. Most of the maps that indigenous and Spanish mapmakers drew during the sixteenth century did not conform to the cartographic canons used in renaissance Europe. In this large corpus we find an exceptional case with all the characteristics of scientific representation, such as the Spanish royal cosmographers hoped the new overseas territories would be mapped: the map of Zapotitlán. Although this document has been studied by several authors, this paper focuses particularly on the cartographic procedures, with new contributions: an analysis of the representation system used, the extent of area represented, and the determination of scale.
\end{abstract}

Keywords: scientific cartography, topographic map, Guatemala, $16^{\text {th }}$ century.

\section{Introducción}

El interés de la Corona española por conocer los recursos humanos y naturales con que contaba el virreinato de Nueva España dio lugar a las importantísimas relaciones geográficas de Indias, elaboradas en el último tercio del siglo XVI, fuente inagotable de la cartografía novohispana. Muchas de estas relaciones venían acompañadas de un plano, mapa o pintura, como entonces se conocían los documentos cartográficos. Tras un detallado estudio sobre la forma de representar el terreno en estos documentos, se puede concluir que, independientemente de si la autoría de estos mapas es española o indígena, en su mayoría no cumplieron con las expectativas de los promotores de la encuesta. Las razones de esta afirmación se basan en que dichos documentos rara vez se vieron precedidos de la medición y toma de datos sobre el terreno y el subsiguiente levantamiento planimétrico a escala. Esto era lo que se esperaba de los documentos gráficos que se obtuviesen de la encuesta de las 
Relaciones Geográficas, al objeto de completar un proyecto de representación del Nuevo Mundo, con el que componer un atlas geográfico y corográfico, para llevar a cabo una descripción rigurosa y precisa del mismo.

Sin embargo, este magno proyecto resultó utópico, se concibió en la metrópolis sin tener en cuenta la realidad al otro lado del Atlántico: las enormes distancias, las grandes extensiones inexploradas, la falta de instrumentos y de personas versadas en las técnicas para realizar levantamientos topográficos, la imposibilidad de resolver problemas cosmográficos como la determinación de las longitudes, etc. Aunque hubo un grupo reducido de hombres que comprendieron, en parte, qué tipo de imágenes, mapas y planos estaba solicitando la Corona, no contaron con los medios humanos y materiales de que dispuso Pedro de Esquivel en la península ibérica. ${ }^{1}$ A diferencia de éste, que pateaba cada palmo de tierra que iba a levantar (Guevara 1788: 220), los cosmógrafos de la Corona responsables del proyecto, Alonso de Santa Cruz, primero, y posteriormente su sucesor Juan López de Velasco; debían trazar el mapa del Nuevo Mundo, mediando un océano de por medio (Mundy 1996: 11). Por tanto, el proyecto de representación del Nuevo Mundo, cubriendo las tierras del interior con todo detalle mediante las relaciones geográficas, fracasó parcialmente, y no parece que haya ninguna prueba de que ese material manuscrito fuera nunca incorporado a los mapas generales.

En general, estas representaciones parciales del interior continental constituyeron, en su conjunto, imágenes que mezclaron dos concepciones del mundo basadas en la tradición española renacentista y en la cultura prehispánica, imbuida de simbolismo. Con todo, el esfuerzo cartográfico realizado por España durante el siglo XVI, ayudado por la contribución indígena, tuvo como resultado un notable conocimiento de las características geográficas de las nuevas posesiones americanas. Sin embargo la mayor parte de estos documentos cartográficos no reunían las características necesarias para que pudiesen encajar como las piezas de un puzle que conformara el deseado mapa detallado del Nuevo Mundo. En todos los mapas y planos que realizaron los pintores indígenas o tlacuilos, así como en la mayoría de los que dibujaron españoles y criollos, fue habitual la ausencia de mediciones, coordenadas geográficas y la utilización de escalas.

De los documentos gráficos que han sobrevivido del corpus de las relaciones geográficas, tan solo unos cuantos se realizaron siguiendo los cánones de la cartografía "racional", a los ojos de lo que en la Europa renacentista se entendía como tal: toma de medidas lineales y angulares sobre el terreno, determinación de coordenadas geográficas y utilización de escala en la realización de los mapas. Este pequeño grupo, quizás el ejemplo más significativo sea el mapa de la Relación de Zapotitlán.

\section{La Relación Geográfica de Zapotitlán}

Al sur de México, en la costa guatemalteca del Pacífico se ubicaba la provincia de Zapotitlán. En el siglo XVI esta región era el centro de la industria del cacao (Morales 2001: 134). La Relación Geográfica de Zapotitlán, corresponde a un área ubicada entre la costa occidental de Guatemala y la cadena volcánica que se alza paralela al litoral (Figura 1). Fechada el 22 de noviembre de 1579, está redactada y firmada por Juan de Estrada y Fernando de Niebla, alcalde mayor y escribano, respectivamente, de la provincia novohispana de Zapotitlán. Cuando se redactó la Relación, la población más importante de esta región era San Francisco de Zapotitlán, de donde tomó la denominación esta provincia del obispado de Guatemala. El documento de la Relación lo componen trece folios de texto en el que se respondía al cuestionario, y un mapa. Actualmente se conserva en la Nettie Lee Benson Latín American Collection de la Biblioteca de la Universidad de Texas en Austin. 


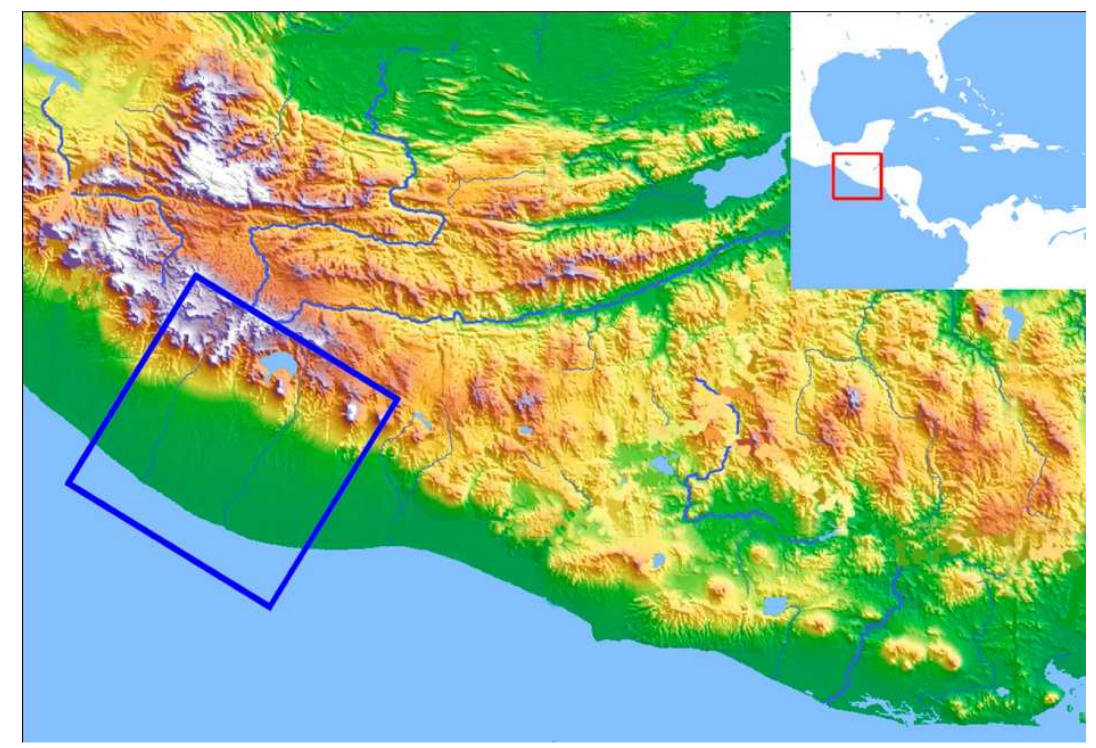

Figura 1. Mapa de situación de la zona representada en el mapa de Zapotitlán. Fuente: Wikimedia Commons y elaboración propia.

\section{El mapa de la costa de Zapotitlán y Suchitepéquez}

El mapa que acompaña a la Relación Geográfica de Zapotitlán está realizado a tinta y acuarela sobre papel europeo (Figura 2). Posee una extensa leyenda en español pero, al igual que en la inmensa mayoría de las pinturas que acompañaron a las Relaciones Geográficas, no está firmado lo que hace unos años motivó alguna que otra controversia sobre su autoría. Así, Donald Robertson, basándose en el texto de la introducción que precede a las respuestas del cuestionario, explicaba en 1972 "The text of Zapotitlan strongly suggests that the scribe, Fernando de Niebla, also made the pintura" (Robertson 1972: 260). Más adelante puntualiza "Probably made by Fernando Niebla, scribe; long text at foot of map explaining geography of the area" (Robertson 1972: 276). Sin embargo diez años más tarde René Acuña se postuló claramente a favor del otro firmante del texto de la Relación, el Alcalde Mayor Juan de Estrada. Acuña basó su conjetura en el hecho de que el autor del texto de la Relación -y probablemente del mapa- poseía "amplios conocimientos de náutica y no poca erudición cosmográfica" (Acuña 1982: 18). Hay una serie de detalles que lo corroboran: su exquisito cuidado al establecer el día solar y lunar, así como la hora precisa de sus observaciones. Incluso llega a citar en el texto del cuestionario una obra del cosmógrafo Jerónimo de Chaves ${ }^{2}$ “....es de advertir en las seis horas que hay de diferencia de España a esta provincia, según lo dice [Jerónimo] Chaves en su Repertorio...” (Acuña 1982: 33). Además por la respuesta a la pregunta seis del cuestionario se deduce que el autor del mapa tenía un astrolabio y sabía hacer uso apropiado de él. 


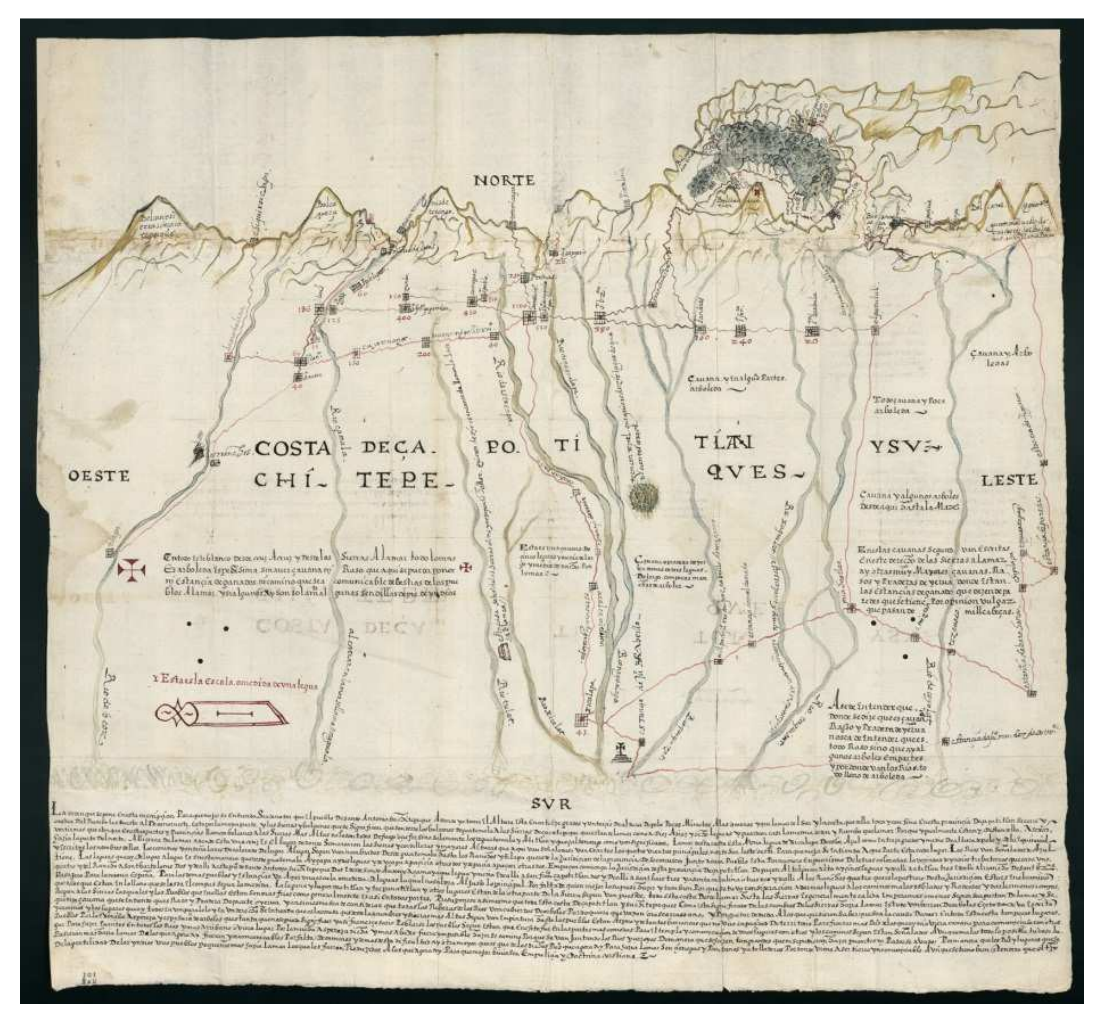

Figura 2. Mapa de la Relación de Zapotitlán y Suchitepéquez, Juan de Estrada 1579. Fuente: Benson Latin American Collection, Austin. Signatura: UTX, JGI xx-9.

Por todos estos datos, René Acuña razona que resulta inexplicable que el redactor del cuestionario y autor del mapa sea Fernando de Niebla, escribano de profesión, apostando por Juan de Estrada. Por su experiencia como marino, oficio en el que había llegado al cargo de capitán, ${ }^{3}$ pudo haber tomado mediciones con su astrolabio para posteriormente levantar el mapa a escala. Otros detalles que hablan de la pericia del autor del mapa son el hecho de señalar con cruces sobre el mapa los puntos precisos desde los que hizo observaciones y tomó apuntes, el sumo cuidado que puso al dejar constancia del punto y la hora en que realizó el estudio de las mareas, etc. René Acuña lo expresaba de esa forma contundente tan característica de Hispanoamérica: "Si, después de reflexionar sobre estos datos, alguien sigue pensando que un simple escribano pudo ser el autor de la relación y también del mapa, lo único que podemos decirle es que su salud mental es de pronóstico reservado" (Acuña 1982: 20). Modernamente el mapa ha sido estudiado por Alexander M. Tait en su tesis doctoral (Tait 1991). Para Tait no existe duda sobre la autoría del mapa en la persona del Alcalde Mayor de Zapotitlán y Suchitepéquez, el capitán Juan de Estrada, marinero experimentado con conocimientos en instrumentos de navegación y cosmografía (Tait 1991: 55). Sin embargo, como el mismo Tait señala, la perfecta ejecución del mapa nos habla no solo de un artífice con amplios conocimientos sobre cartografía náutica -como era de esperar de un marino del siglo XVI- sino también en un agrimensor formado en Europa y versado en levantamientos a escala, con capacidad para hacer no solo una representación de las costas sino también mapas topográficos del territorio interior.

El mapa de Zapotitlán y Suchitepéquez complementa sustancialmente los datos que contiene el texto de la relación, ${ }^{4}$ ya que describe la hidrografía, orografía, topografía y toponimia de la región, así como la situación de los pueblos, encomiendas y estancias, proporcionado además información no geográfica como los nombres de propietarios, número de 
vecinos o tributarios, etc. (Acuña 1982: 19). Además de la información escrita que proporciona sobre distancias entre distintos lugares, el mapa está levantado a escala e incluye una escala gráfica de leguas (Figura 3e). Comparando este documento cartográfico con un mapa topográfico actual de la región se puede estimar que su escala es aproximadamente de 1:275000. ${ }^{5}$ Orientado al norte, en la parte superior se representan las cimas de la cordillera volcánica de Guatemala, que discurre paralela a la línea de costa, en la parte inferior, y con un dibujo muy tenue, casi imperceptible, se dibuja la costa del Pacífico. El mar se representa por el dibujo de unas volutas o espirales paralelas a la playa (Figura 3g). Una extensa leyenda en la parte inferior ocupa todo el ancho del mapa y aproximadamente $1 / 6$ de su altura. El sistema de representación utilizado por Juan de Estrada es lo más parecido a lo que hoy se conoce como proyección egipcia o de Hejduk. ${ }^{6}$

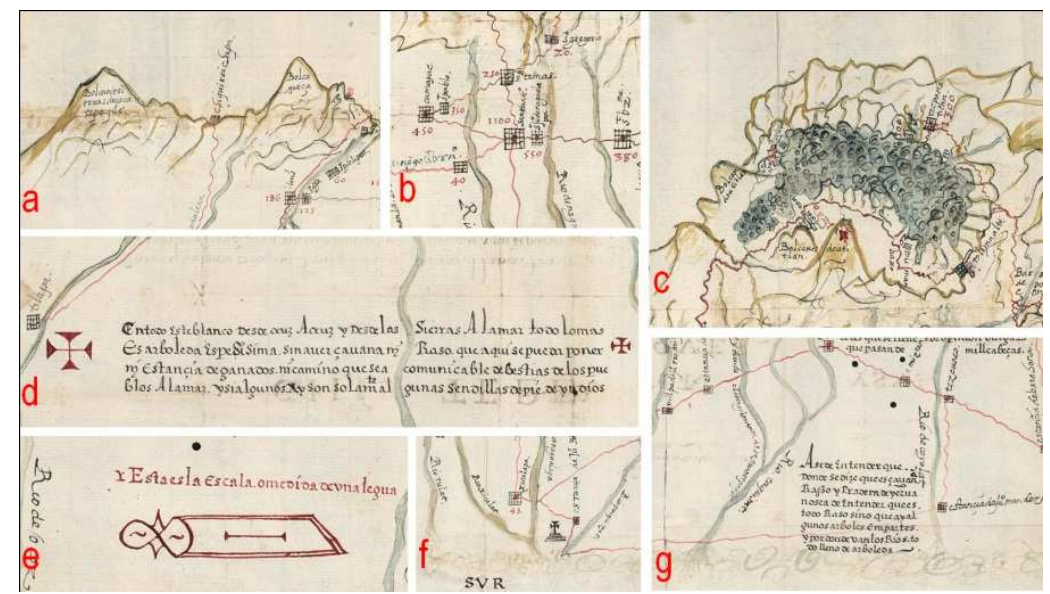

Figura 3. Mapa de la Relación de Zapotitlán y Suchitepéquez. Detalles.

Efectivamente, en los dos tercios inferiores del mapa se representa la región mediante su proyección horizontal o ignográfica; con la red hidrográfica, los distintos pueblos asentados en la provincia con sus topónimos, junto a los que se rotula con tinta roja del número de habitantes (Figura 3f). A diferencia de lo que puede observarse en la mayoría de mapas de las Relaciones Geográficas de Indias, en los que las poblaciones se representaron por el alzado abatido (elevación) de uno o varios edificios representativos de las mismas -generalmente la iglesia o el monasterio-; en este mapa los pueblos se han representado por la proyección horizontal de una simbólica red de calles ortogonales o tablero de ajedrez, recordando la cuadrícula de calles perpendiculares, típica del urbanismo español en América (Figuras $3 \mathrm{~b}$ y f). Una red de caminos unen los distintos pueblos, sin que encontremos indicios de la utilización de la característica convención indígena de las pisadas de un pié desnudo junto a su trazado. La vegetación no se representa gráficamente, sino a través del texto de las inscripciones: "poca arboleda", "algunos árboles", "sabana", "pradera de yerba", etc.

En el tercio superior del mapa se representa la impresionante cordillera volcánica de Guatemala, a través del perfil abatido de sus estribaciones (Figura 3a), de las que emergen los múltiples ríos que vierten sus aguas en el Pacífico recorriendo la región perpendicularmente a la línea de costa. De izquierda a derecha -entre paréntesis se indican los nombres actuales: Ocoz (Ocosito), Samala (Samalá), Tulat (Sis), Xicalat (Icán), Nagualape (Nahualate), ¿Quigozat? (Atitlán), ¿Xaguilat? (Madre Vieja) y Coyolat (Coyolate). La transición entre planta y perfil 
abatido se ha realizado de manera bastante natural, fusionándose ambos sistemas de representación; de forma que el dibujo podría pasar por una vista panorámica desde la costa de la cadena volcánica y la planicie costera que se extiende entre ésta y el océano (Figura 6).

En la parte superior derecha se observa una mancha oscura rodeada de montañas: el lago Atitlán, situado tras los volcanes Atitlán y Tolimán (Figuras 3c y 5). A la izquierda del lago puede verse el volcán de Quezaltenango y a la derecha los volcanes de Guatemala. Junto a estas elevaciones, representadas en perfil abatido, unas inscripciones en español indican: "Volcanes de Atitlán", "Volcanes de Guatemala", "Guatemala está detrás de estos dos volcanes, en un llano bajo". En la Figura 4 se reproduce un mapa físico actual de la mitad sur de Guatemala en el que se han marcado cuatro puntos identificados en las leyendas del mapa de Zapotitlán y Suchitepéquez de 1579: Tilapa, junto a una de las cruces, y la desembocadura del río de Ocoz, actual Ocosito (1), sierra de Sacatepéquez (2), volcanes de Guatemala (3) y desembocadura del río de Coyolat, actual Coyolate (4). Estos puntos extremos delimitan la región representada en dicho mapa, que abarca un área aproximada de $8.200 \mathrm{Km}^{2}$ y un perímetro de $360 \mathrm{Km}$.

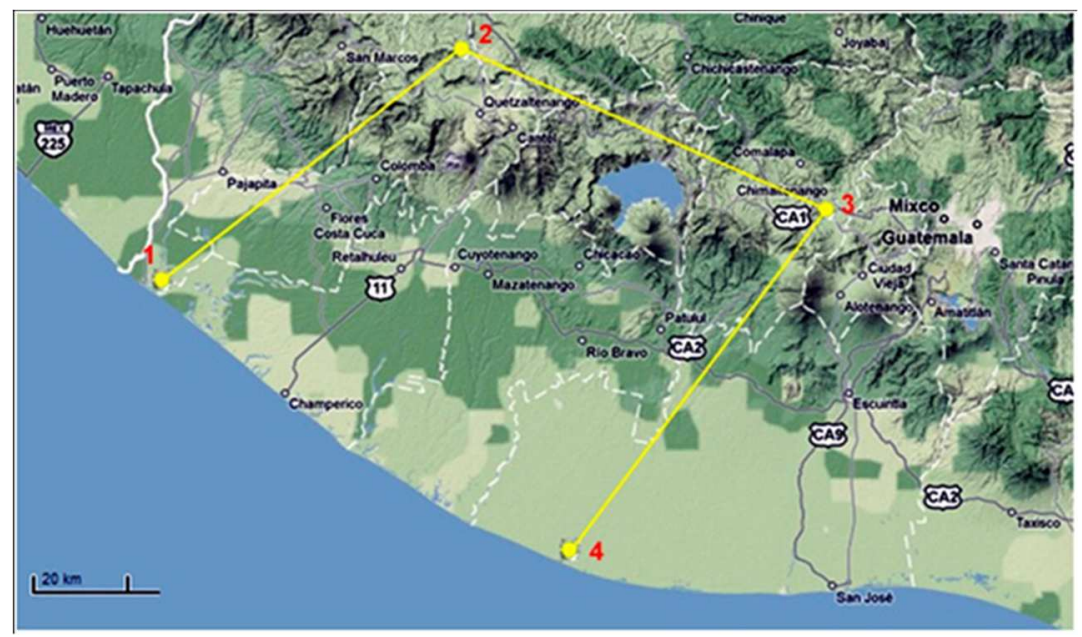

Figura 4. Mapa físico del sur de Guatemala. Se han señalado los puntos correspondientes a cuatro topónimos situados en los extremos del mapa de 1579.

(Fuente: Google Maps y elaboración propia.)

El método de los perfiles abatidos es el procedimiento más antiguo para representar el relieve. ${ }^{7}$ Su utilización está datada casi desde los orígenes de la cartografía -aparece ya en los primitivos mapas babilonios- y fue el más utilizado durante los siglos XVI y XVII, prolongándose su uso hasta finales del siglo XVIII cuando comenzó a ser sustituido gradualmente por las curvas de nivel. El método consiste en dibujar las montañas abatidas, como si estuviesen vistas hacia arriba desde el valle, de forma que la representación de la altimetría se reducía al dibujo del relieve aparente. En la cartografía colonial hispanoamericana es un método utilizado tanto en los mapas de factura española como indígena. Asimismo, también encontramos esta convención en las representaciones del paisaje presentes en los códices prehispánicos, empleándose tanto para las elevaciones del terreno como para la vegetación y las figuras de personas y animales. En la cartografía indígena del periodo colonial, una de sus convenciones más singulares es el tepetl, símbolo vernáculo para representar el cerro o la montaña, que se ha identificado con el dibujo de un ánfora. En esencia, no deja de ser un dibujo en alzado abatido. 
En el mapa de Zapotitlán la convención de los perfiles abatidos solo se ha empleado para la cadena volcánica que delimita el dibujo por su parte superior. En el resto del mapa se utiliza la representación planimétrica del territorio, tanto para la completa red hidrográfica como para las poblaciones y los caminos. Una sola excepción nos confirma esta regla: la Cruz de Malta que señala el lugar donde se situó el cartógrafo para tomar nota de las alturas de las montañas, que se representa por su alzado (Figura 3f). En el conjunto de elevaciones que constituyen la cordillera volcánica de Guatemala, representada por sus perfiles abatidos, el autor de mapa introduce la imagen planimétrica del lago Atitlán, de forma que se alternan en el dibujo la representación planimétrica o ignográfica en los dos tercios inferiores, el perfil abatido en el tercio superior, en el que de nuevo se introduce la ignografía para representar el lago. Como señala Tait, la transición entre estos sistemas de representación se realiza de forma bastante natural (Tait 1991: 56), de manera que el mapa en su conjunto ofrece el aspecto de una vista panorámica de los volcanes y la franja que se extiende entre ellos y la costa, tomada desde un punto de vista elevado situado sobre el mar. Sin embargo, hay que señalar que no existe ningún punto de vista "real" desde el que se pueda observar simultáneamente el perfil de los volcanes -representación en alzado- y la planta del lago. Véase la Figura 4, donde puede contemplarse la región desde un punto de vista muy elevado, lo que hace que el lago Atitlán se vea a vista de pájaro, mientras que las montañas no muestran su perfil, sino su proyección horizontal. La orografía de los volcanes sería imperceptible si no fuese por el recurso pictórico del sombrado, que da al dibujo sensación de tridimensionalidad. A pesar de que no se indica de forma textual la escala empleada para el levantamiento del mapa, sí que se incluye en la parte inferior izquierda una escala gráfica de leguas (Figura 3e), como por otra parte era habitual en los mapas y planos que se hacían en Europa en el siglo XVI.

La extensa leyenda de la parte inferior del mapa contiene datos sobre la realización del mismo, ${ }^{8}$ como el resultado de la medición de la altura del polo y el pueblo donde se tomó, los límites geográficos de la zona representada y sus distancias: “...la Mar del Sur, y la costa que della toca y confina esta provincia de Zapotitlán, se corre y costea del rumbo les-sueste al de os-noreste. Esto por la mayor parte e igual que las sierras y volcanes que se significan, que son desde los volcanes de Guatemala a las sierras de Sacatepéquez, que están de la mar como a diez y ocho leguas...". También nos aclara el alcance de alguno de los términos utilizados en las leyendas: "... aunque en estas partes y provincias llaman volcanes a las sierras más altas, no lo son todos de fuego o azufre, sino solamente Guatemala y Atitlán y Quezaltenango...”. Asimismo explica el significado de la Cruz de Malta dibujada en la parte inferior izquierda del mapa (Figura 3d): “...cerca del mar, donde está la cruz, es el lugar desde donde se marcaron las sierras y cordilleras y las mayores alturas que aquí van señaladas". Nos encontramos con una prueba evidente, de primera mano, de que se realizaron observaciones y mediciones tanto astronómicas como directas sobre el terreno para levantar un mapa local, hecho excepcional en la cartografía hispanoamericana de época colonial.

También se explica en la leyenda escrita en la parte inferior del mapa el significado de los colores utilizados: "La mar desta costa está a una legua de Xicalapa, de color azul, como en trece grados del Polo y, de la [línea] equinoccial, hacia la parte del norte. [...] Los ríos van señalados de azul, y escritos los nombres dellos. Los caminos van señalados de colorado, de lugar a lugar,...". También se aportan datos sobre distancias entre lugares y demográficos: “...junto a cada pueblo está por número, en guarismo de letras coloradas, la vecindad de indios tributarios que cada uno tiene. Las leguas que hay de lugar a lugar es en esta manera: que, desde Guatemala a Izapa, hay dos leguas; y, de Izapa a Patzicía, otras dos, [...] Para los demás pueblos y estancias, va aquí una escala o medida en leguas, la cual no saldrá al justo, lo principal por falta de quien mejor lo supiese hacer..." 


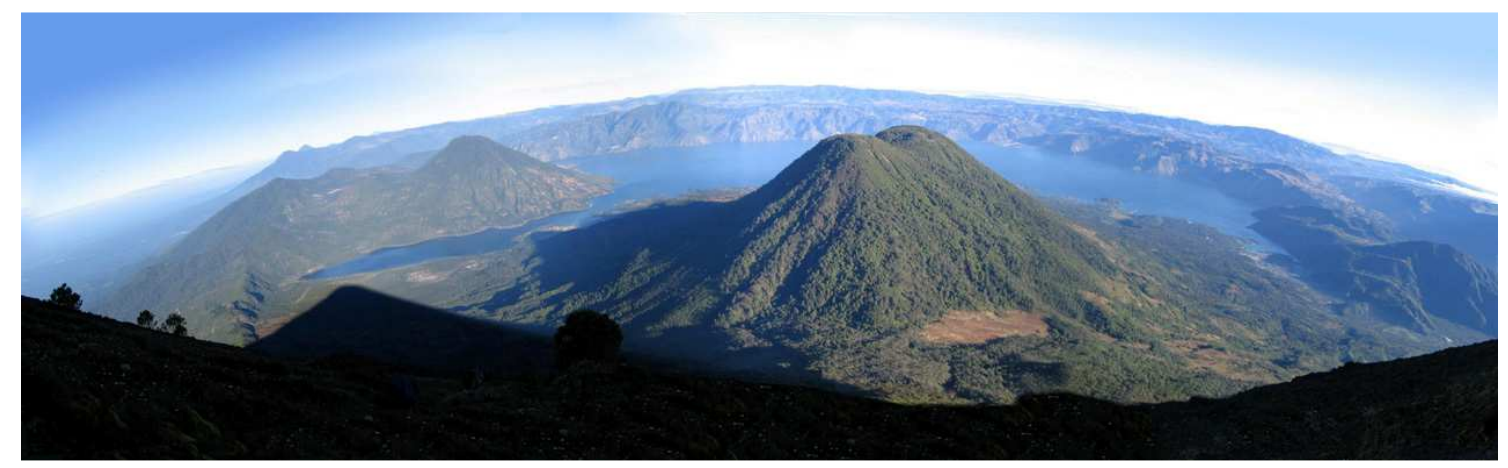

Figura 5: Lago Atitlán, flanqueado por los volcanes Atitlán y Tolimán, a la derecha, y San Pedro, a la izquierda. (Fotografía: Luis Pablo Salazar. Fuente: Google Panoramio.)

Tras tratar sobre el clima de la región, el autor del mapa también nos desvela en su extensa leyenda la razón por la que no vemos vegetación representada:

"Presupónese, así mesmo, que toda esta costa de Zapotitlán y Suchitepéquez, como está significado, de las cumbres de las sierras hacia el mar, es todo un borrón de árboles, excepto donde va escrito y dice sabana, que se entiende que es raso y pradera de qacate o yerba. Y, ansí mesmo, se ha de considerar que todas las riveras de los ríos van cubiertas de árboles por doquiera que estos vayan, ora sea raso o no."

Finalmente explica la razón de que en toda la costa hasta las sierras haya tan pocos caminos y lugares habitados: “...es tan áspero y de tantas barrancas, que no hubo capacidad de territorio para fundar más pueblos de los que hay, ni hubiera camino para comunicarse con otros pueblos por la excesiva aspereza y espesura de árboles, [...] Y, demás desta dificultad, hay otra mayor, que es que, desde los dichos que ahora hay hacia el mar, todo son ciénagas y pantanos y atolladeros, por donde viene a ser tierra incomunicable...". Todavía hoy podemos comprobar que en estos humedales inundables no debió ser fácil fundar poblaciones:

\section{Consideraciones finales}

Aunque los cosmógrafos de la Corona española que idearon la encuesta de las Relaciones Geográficas tuvieron como objetivo principal el conformar un mapa detallado de los nuevos territorios americanos que pertenecían al imperio de Felipe II, lo cierto es que la mayoría de las pinturas que llegaron a la Península acompañando a las respuestas a las Relaciones Geográficas no sirvieron para ese objetivo. Una premisa fundamental para que ese material cartográfico fuese útil para formar el mapa detallado del Nuevo Mundo era la indicación de las coordenadas geográficas de longitud y latitud, la medición de distancias y ángulos sobre el terreno -lo que implica la utilización de instrumentos topográficos- y su posterior traslado al mapa siguiendo una escala determinada e indicada en el propio documento, que hiciese reversible el proceso de representación.

Los mapas que realizaron los pintores indígenas o tlacuilos, a pesar de que la mayoría fueron formados en las escuelas monásticas (Mundy 1996: 76), combinaron elementos de 


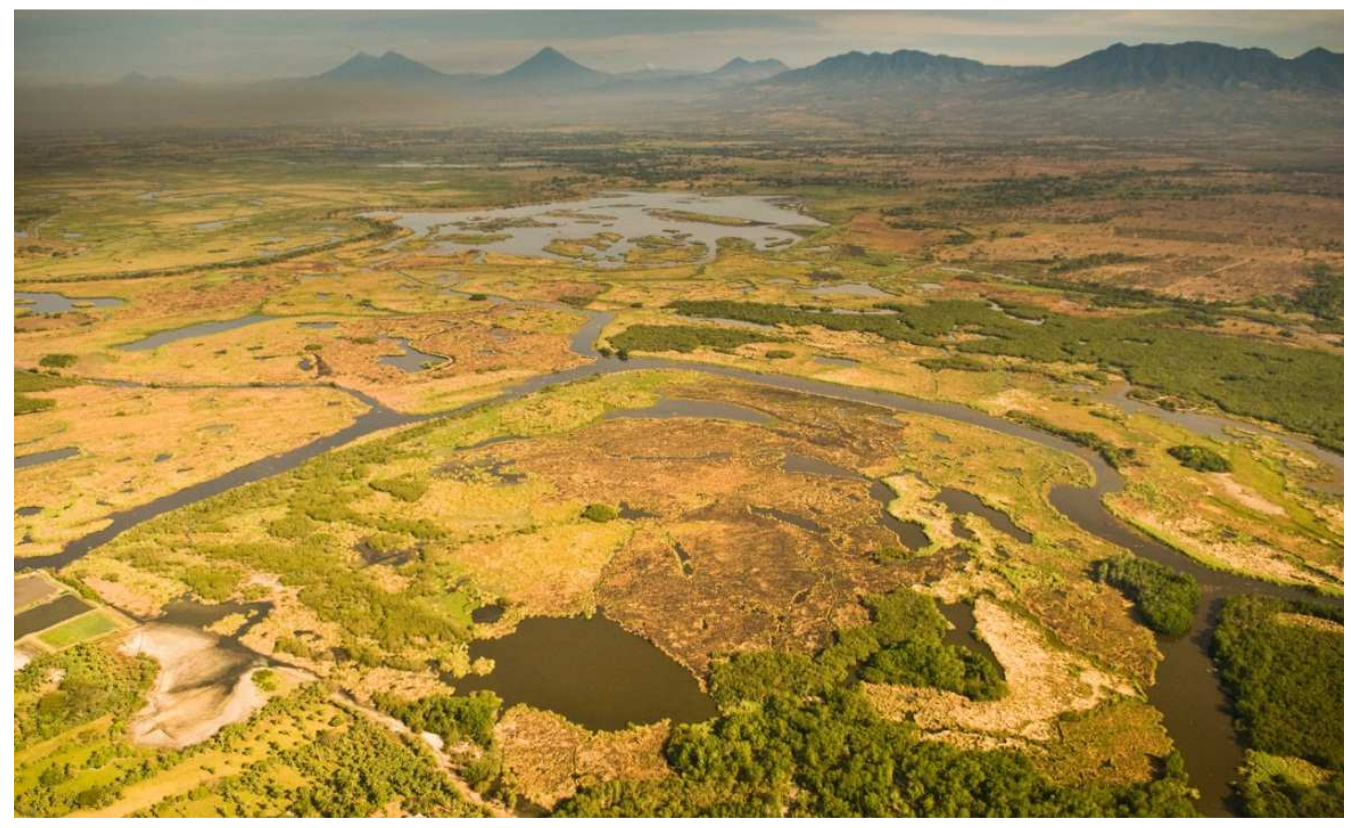

Figura 6. Zona de marismas y humedales en la planicie costera, con la cordillera volcánica al fondo. (CAVU Photo. Fuente: Google Panoramio.)

origen diverso, unos españoles y otros prehispánicos, caracterizados por la utilización de un arte conceptual, pictográfico, apoyado en esquemas, convencionalismos o sugerencias de una inmediata lectura; y otros recién inventados en el contexto colonial, lo que implica una cierta facilidad de manipular distintos modelos y técnicas visuales. En estas pinturas no hay ninguna referencia a la escala, ni mucho menos a datos que permitan referenciar la zona representada en un sistema general, como las coordenadas geográficas. Es muy difícil suponer que estos artistas recibieran la influencia de las técnicas cartográficas y topográficas del siglo XVI, que apenas empezaban a establecerse en España a finales de dicha centuria.

Cabe ahora preguntarse si la difusión de estos métodos alcanzó al Nuevo Mundo y, sobre todo, si fue tan intensa que pudiera haber permitido al grupo de dibujantes españoles y tlacuilos manejar la instrumentación requerida y los procedimientos cartográficos. Para poder realizar levantamientos topográficos como los que se describieron en Europa en el siglo XVI, era necesario contar con conocimientos matemáticos de geometría y, especialmente, de trigonometría. No podemos despreciar el vasto conocimiento matemático de los pueblos prehispánicos, pero tampoco podemos asegurar que los tlacuilos del siglo XVI conservaran dicho conocimiento. Cabe la posibilidad de que consultaran libros europeos sobre matemáticas, donde habrían podido encontrar instrucciones geométricas aplicables al levantamiento de mapas y planos (Montes de Oca 2003: 165).

Si pensamos que por vía de los libros, presentes en las bibliotecas monásticas, se hubiesen podido difundir los métodos de levantamiento topográfico, entonces en las colecciones que atesoraron los monasterios durante el siglo XVI, se encontrarían obras de reputados cosmógrafos europeos, como Alberti, Apiano, Bartoli o Fineo; y españoles como Rojas Sarmiento o Pérez de Moya; algo que por el momento no se ha demostrado, a falta realizar una exploración más minuciosa. ${ }^{9}$ A esto debemos añadir que en Nueva España se elaboraron gran cantidad de mapas, en los que deberían existir rastros o indicios del uso de los instrumentos requeridos por los métodos europeos: trazos de las triangulaciones, notas de observaciones sobre los mapas, de conversiones entre los sistemas de medición de ángulos, o cualquier otra pista; nada de esto se ha encontrado. Al menos entre los artistas y dibujantes 
indígenas de Nueva España, no se tienen noticias sobre el uso, compra, venta o manufactura de la instrumentación topográfica básica del siglo XVI; al contrario, parece que tanto los mapas que se elaboraron para anexionarse a las solicitudes de mercedes de tierras, como a los cuestionarios de las Relaciones Geográficas de Indias, se realizaron sin la sistematización de estos métodos (Montes de Oca 2003: 165).

Los mapas que realizaron los propios funcionarios de la administración indiana, o que encargaron a españoles y criollos, tampoco cumplieron con las expectativas de los promotores de la encuesta. Juan López de Velasco imaginó a los funcionarios locales encargados de responder a las Relaciones como "personas con conocimientos sobre las cosas de la tierra" (Mundy 1996: 23), sin embargo muchos de los documentos cartográficos realizados por estos corregidores y alcaldes mayores fueron muy rudimentarios, presentando un estilo tosco y carente de los elementos básicos necesarios para lo que cabría esperar de un mapa racional: toma de datos, escala y el cálculo de las coordenadas geográficas.

Esta determinación de las coordenadas geográficas de latitud y longitud de los distintos lugares fue una de las mayores preocupaciones científicas durante todo el siglo XVI. La obtención de la de latitud se relacionó directamente con la observación del Sol durante el día o de la Estrella Polar durante la noche. El problema de la determinación de la longitud, científica y tecnológicamente más complicado, quedó aparentemente solucionado por la observación astronómica de los eclipses lunares. El cálculo de la longitud mediante la observación de eclipses ya había sido sugerido por los griegos de la Antigüedad, la diferencia en el tiempo de un eclipse lunar visto desde dos lugares diferentes indicaría su diferencia en longitud. Como correctamente comentó Santa Cruz, esto no era muy útil para las necesidades continuas de los navegantes, ya que los eclipses eran fenómenos infrecuentes. Pero además, este método tenía otros inconvenientes pues, como comprendió claramente el cosmógrafo real, era esencial asegurarse de que estaba siendo cronometrada la misma fase del largo proceso de un eclipse en los dos lugares en cuestión. Un error de tan solo pocos minutos en la medida del tiempo acarrearía grandes errores en la longitud..$^{10}$ A pesar de estas dificultades, Alonso de Santa Cruz ideó para las Indias un cuestionario que debía ser remitido a los navegantes y descubridores. Sin embargo, no sería hasta entrado el siglo XVIII cuando se logró medir exactamente la longitud, estableciéndose un método práctico a partir de que se pudo contar con cronómetros de precisión y portátiles, que permitieron una medición precisa del tiempo en cualquier lugar.

En este panorama, el mapa de Zapotitlán constituye un ejemplo paradigmático de cartografía científica en el corpus de las relaciones geográficas del siglo XVI. La descripción detallada del territorio da testimonio de una sorprendente precisión planimétrica que, aunque no es difícil de encontrar en los levantamientos territoriales que se realizaron en Europa durante el Renacimiento; es prácticamente inexistente en la cartografía colonial hispanoamericana. El mapa de la relación geográfica de Zapotitlán no solo nos habla de un detallado conocimiento de la región representada, sino de la utilización de técnicas topográficas equiparables a las más avanzadas que se desarrollaban y difundían por Europa durante el siglo XVI. Esto debió suponer obligatoriamente la utilización de instrumentos para el posicionamiento general (observaciones astronómicas para la determinación de las coordenadas geográficas, como la ballestilla o el astrolabio); así como la realización de mediciones locales tanto de ángulos como de distancias (en las operaciones de agrimensura que se realizaron en Europa durante los siglos XV y XVI se utilizaron sistemas de medición directas e indirectas, con la ayuda de instrumentos como el goniómetro, el cuadrante geométrico, el astrolabio o la ballestilla). ${ }^{11}$ Basándose en la toma de datos sobre el terreno, Juan de Estrada elaboró su mapa con una más que aceptable exactitud planimétrica a la vez que con un marcado sentido corográfico, resultando una original vista panorámica de la región. Esta imagen nos ofrece 
mayor cantidad de información que la que se pudiera obtener con una moderna fotografía de gran angular de la zona, pues como se ha señalado, desde el mar puede observarse la cadena montañosa de los volcanes, pero es imposible ver el lago Atitlán, cosa que el autor del mapa consigue con una sorprendente naturalidad.

Desafortunadamente no se han encontrado vestigios que pudieran aportar detalles sobre los métodos seguidos para el levantamiento este mapa, ni de ningún otro perteneciente al corpus de las relaciones geográficas, ni en el vasto conjunto de documentos cartográficos de tradición hispano indígena (Montes de Oca 2003: 165), como pudieran ser anotaciones de campo sobre mediciones, croquis o dibujos previos, restos de trazados en el propio mapa apoyados en la aritmética, la geometría y la trigonometría, esbozos de triangulaciones, cálculos sobre la obtención de medidas longitudinales a partir de otras angulares, etc.

\section{Agradecimientos}

El autor desea agradecer a la Biblioteca de la Universidad de Texas en Austin, especialmente al Dr. Michael Hironymous, Library Assistant, Benson Latin American Collection, su inestimable ayuda al facilitarme una reproducción en alta definición del mapa de Zapotitlán, sin la cual no hubiese podido llevarse a cabo este estudio.

\section{Notas}

${ }^{1}$ Pedro Esquivel fue Catedrático de Matemáticas en la Universidad de Alcalá de Henares, su ciudad natal. Como cosmógrafo, estuvo al servicio de Carlos V y de su hijo Felipe II, quien le encargó la realización de un mapa geodésico de España, que se inició en 1551 y quejó inacabado a su muerte, en 1570.

2 Jerónimo de Chávez (1523-1574), fue matemático, astrólogo, estudioso de las artes y la medicina, traductor de obras científicas italianas, catedrático y cosmógrafo de la Casa de la Contratación de Sevilla desde 1552. En 1548, a la edad de 25 años, publicó su primera Chronographia, obra que tuvo un enorme éxito y de la que se hicieron doce ediciones en 40 años, siempre con privilegio real.

${ }^{3}$ Sobre el oficio -capitán- y cargo -alcalde mayor de Zapotitlán- de Juan de Estrada, véase: AGI, Patronato, 293, N.1, R.3. "Real Provisión al capitán Juan de Estrada, concediéndole el título de alcalde mayor de la provincia de Zapotitlán" San Lorenzo de El Escorial, 25-VI1578.

${ }^{4}$ Aunque Zapotitlán era el nombre de la provincia descrita en la Relación y San Antonio Suchitepéquez un pueblo de la misma, el nombre del lugar que figura en el texto original es “...provincia y costa de Zapotitlán y Suchitepéquez". Además en el mapa que acompaña a la Relación se rotuló "Costa de Zapotitlán y Suchitepéquez".

${ }^{5}$ Para determinar la escala del mapa de la Relación Geográfica de Zapotitlán hemos realizado un estudio topográfico comparativo entre las distancias reales y las medidas sobre el mapa entre dos puntos de referencia: las desembocaduras de los ríos Ocosito y Coyolate. Asimismo también se han comparado la escala gráfica del mapa y el valor de una legua castellana del siglo XVI (entre 5.573 y 5.914 metros).

${ }^{6}$ La perspectiva de Hejduk -John Quentin Hejduk (1929-2000)- o egipcia, consiste en una proyección cilíndrica oblicua de tipo militar, en que la dirección de proyección del eje que 
determina la altura se realiza paralelamente a una de las direcciones de la base, de forma que la planta y el alzado se proyectan sin deformación.

${ }^{7}$ De forma resumida, los distintos modos de representar la altimetría fueron apareciendo a lo largo de la historia según el siguiente orden. Alzados o perfiles abatidos: fue muy empleada desde los orígenes de la representación territorial (plano de Nuzi, 2500 a. C.), durante todo el Renacimiento y continuó utilizándose hasta el final del siglo XVIII. Perspectiva paralela utilizando un punto de vista elevado, vista panorámica o paisajista: comienza a utilizarse en el periodo renacentista, es una representación más realista de las formas del terreno que surge cuando los científicos y artistas empezaron a interesarse por la representación de la orografía del paisaje.

${ }^{8}$ La extensa leyenda escrita en la parte inferior del mapa también explica el significado de algunos de los colores utilizados en el mismo: los ríos en azul y los caminos en rojo.

${ }^{9}$ En el monasterio franciscano de Santiago Tlatelolco (situado en el actual estado mexicano de Jalisco) existieron dos libros de cosmografía que tuvieron tan poco uso que en 1584 "se vendieron por inútiles" (García Icazbalceta 1892: 262). Citado por Mundy 1996: 57 y por Montes de Oca Vega 2003: 165.

${ }^{10}$ Sobre la determinación de la longitud utilizando la observación de los eclipses de luna, véase: Rodríguez Sala, María Luisa. 1998. El eclipse de Luna: misión científica de Felipe II en Nueva España. Huelva: Universidad de Huelva.

${ }^{11}$ Sobre las técnicas de levantamiento y representación del territorio en Europa durante el Renacimiento véase: Morato 2010: 151-195.

\section{Bibliografía}

Acuña Sandoval, René. 1985. Relaciones Geográficas del siglo XVI: Tlaxcala; vol. 5. México: Universidad Nacional Autónoma de México.

Estrada, Juan de. 1955. Descripción de la provincia de Zapotitlán y Suchitepéquez, año de 1579, por su Alcalde Mayor, capitán Juan de Estrada y el escribano Fernando de Niebla, Anales de la Sociedad de Geografía e Historia de Guatemala, Vol. 28: 68-84.

García Icazbalceta, Joaquín. 1892. Nueva colección de documentos para la bistoria de México: Códice Mendieta: documentos franciscanos, siglos XVI y XVII. México: Andrade y Morales, sucesores.

Guevara, Francisco de y Ponz, Antonio (ed.). 1788. Comentarios de la pintura. Madrid: Don Gerónimo Ortega, hijos de Ibarra y Compañía.

Montes de Oca Vega, Mercedes. 2003. Cartografía de tradición hispano indígena: mapas de mercedes de tierra, siglos XVI y XVII, Vol. 1. México: Universidad Nacional Autónoma de México.

Morales Folguera, José Miguel. 2001. La construcción de una utopía. El proyecto de Felipe II para Hispanoamérica. Málaga: Servicio de Publicaciones de la Universidad de Málaga. 
Morato Moreno, Manuel. 2010. La representación gráfica en la América hispana del siglo XVI: fortificaciones y terrenos. Tesis doctoral, Departamento de Expresión Gráfica Arquitectónica, Universidad de Sevilla, Sevilla, España.

Mundy, Barbara E. 1996. The mapping of New Spain. Indigenous Cartography and the Maps of the Relaciones Geográficas. Chicago: the University of Chicago Press.

Robertson, Donald. 1972. The Pinturas (Maps) of the Relaciones Geográficas, with a Catalog. Handbook of Middle American Indians, vol. 12, H. F. Cline y R. Wauchope (eds.), pp. 243278. Austin: University of Texas Press.

Rodríguez Sala, María Luisa. 1998. El eclipse de Luna: misión científica de Felipe II en Nueva España. Huelva: Universidad de Huelva.

Tait, Alexander M. 1991. Cartography and colonial society : Maps of the Relaciones Geográficas of Mexico and Guatemala. Tesis doctoral, Universidad de Wisconsin, Madison, USA. 